\title{
The efficiency of short sintering time on thermoelectric properties of delafossite $\mathrm{CuCr}_{0.85} \mathbf{M g}_{0.15} \mathrm{O}_{2}$ ceramics
}

\author{
Dung Van Hoang ${ }^{1,2,3,{ }^{*}}$, Truong Huu Nguyen ${ }^{1,2}$, Anh Tuan Thanh Pham ${ }^{1,2}$, Thu Bao Nguyen Le ${ }^{2,4}$, \\ Vinh Cao Tran ${ }^{1,2}$, Thang Bach Phan ${ }^{1,2,3}$
}

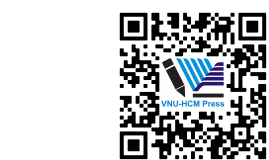

Use your smartphone to scan this QR code and download this article

\section{${ }^{1}$ Laboratory of Advanced Materials, University of Science, Ho Chi Minh City, Viet Nam}

${ }^{2}$ Vietnam National University Ho Chi Minh City, Viet Nam

${ }^{3}$ Center for Innovative Materials and Architectures, Ho Chi Minh City, Viet Nam

${ }^{4}$ Department of Mathematics and Physics, University of Information Technology, Ho Chi Minh City, Viet Nam

\section{Correspondence}

Dung Van Hoang, Laboratory of Advanced Materials, University of Science, Ho Chi Minh City, Viet Nam

Vietnam National University Ho Chi Minh City, Viet Nam

Center for Innovative Materials and Architectures, Ho Chi Minh City, Viet Nam

Email: hvdung@hcmus.edu.vn

History

- Received: 2021-01-26

- Accepted: 2021-05-09

- Published: 2021-05-12

DOI : 10.32508/stdj.v24i2.2512

\section{Check for updates}

\section{Copyright}

(c) VNU-HCM Press. This is an openaccess article distributed under the terms of the Creative Commons

Attribution 4.0 International license.

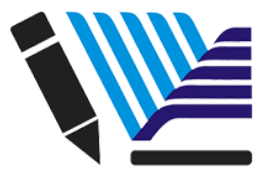

VNU-HCM Press

\begin{abstract}
Introduction: Harvesting the waste heat emitted from the activities of humanity based on thermoelectric devices is an appropriate way to reduce the overconsumption of fossil fuel nowadays. Methods: In this work, $\mathrm{CuCr}_{0.85} \mathrm{Mg}_{0.15} \mathrm{O}_{2}$ compounds prepared by conventional solid-state reaction method were investigated to find out that the short sintering time is enough for thermoelectric applications, directly low the cost of the devices. Results and Conclusion: We find out that there is a significant change in the crystal structure, the chemical state, and thermoelectric properties along with the increase of the sintering time, but eventually, the dimensionless figure of merit ZT is almost constant regardless of the long or short sintering time which means that the increase of electrical conductivity will compromise the increase of thermal conductivity. The highest ZT value is 0.03 measured at $500^{\circ} \mathrm{C}$ for both samples prepared at the sintering time of 3 and 12 hours.

Key words: CuCr0.85Mg0.15O2 ceramics, sintering time, thermoelectric properties, solid-state reaction method, $\mathrm{ZT}$
\end{abstract}

\section{INTRODUCTION}

Thermoelectric materials have recently emerged as a potential candidate for harvesting the waste heat from artificial sources: vehicles using the robust engines, thermal power plants, ... or natural sources: geothermal or solar energy. Thermoelectric devices convert heat energy based on the dimensionless figure of merit $\mathrm{ZT}=\sigma \cdot \mathrm{S}^{2} \cdot \mathrm{T} /\left(\kappa_{e}+\kappa_{l}\right)^{1}$, where $\sigma(\mathrm{S} / \mathrm{cm})$ is electrical conductivity, $\mathrm{S}(\mu \mathrm{V} / \mathrm{K})$ is Seebeck coefficient, $\kappa_{e}$ is electron thermal conductivity and $\kappa_{l}$ is lattice thermal conductivity. Therefore, a material that serves for thermoelectric device needs the ZT value is as high as possible. Hence, the transport parameters (Seebeck coefficient, electrical, and thermal conductivity) need to be improved. However, these transport parameters commonly vanish to each other (e.g., the increase of electrical conductivity as elevating temperature gives rise to the decrease of Seebeck coefficient and the growth of thermal conductivity because of bipolar effect ${ }^{1}$ ). Therefore, it is important to explore a material that could compromise those transport parameters.

Recently, oxide materials emerge as a potential candidate for thermoelectric applications due to their advantages: (i) the stability of oxide compounds when it is exposed on ambient air at high temperature led to enhance the $\mathrm{ZT}$ value as following equation ${ }^{1}$; (ii) the raw materials have low cost and environmental friendliness ${ }^{2}$. There are a number of thermoelectric oxide materials reported with high thermoelectric performance, such as $\mathrm{SrTiO}_{3}, \mathrm{Ca}_{3} \mathrm{Co}_{4} \mathrm{O}_{9}, \mathrm{Na}_{x} \mathrm{CoO}_{2}$, $\mathrm{ZnO}, \mathrm{In}_{2} \mathrm{O}_{3}$, and $\mathrm{BiCuSeO}^{3}$. Among them, the layered cobalt oxides $\left(\mathrm{Ca}_{3} \mathrm{Co}_{4} \mathrm{O}_{9}\right.$ and $\left.\mathrm{Na}_{x} \mathrm{CoO}_{2}\right)$ are known as good $p$-type thermoelectric oxide material at high temperatures around $700-1000 \mathrm{~K}^{2,4}$. However, it is noted that $\mathrm{Na}_{x} \mathrm{CoO}_{2}$ will be decomposed into insulating $\mathrm{Co}(\mathrm{OH})_{2}$ as being exposed in a high humidity environment ${ }^{2}$. In the case of the $\mathrm{Ca}_{3} \mathrm{Co}_{4} \mathrm{O}_{9}$ compound, the anisotropic electric properties are caused by its crystal structure and the less densification because of the large difference of temperature between the eutectic point and the stable range of $\mathrm{Ca}_{3} \mathrm{Co}_{4} \mathrm{O}_{9}$ phase are the two main disadvantages of this material ${ }^{5}$. Delafossite, known as an inherited p-type material, has the layered-type structure belonged to cobaltite oxide family like $\mathrm{Ca}_{3} \mathrm{Co}_{4} \mathrm{O}_{9}$ and $\mathrm{Na}_{x} \mathrm{CoO}_{2}$. The crystal structure of delafossite which has the general chemical formular is $\mathrm{ABO}_{2}$ (where $\mathrm{A}$ is $\mathrm{Cu}, \mathrm{Ag}, \mathrm{Pd}$ or Pt and $\mathrm{B}$ is group III elements in the periodic table) is the alternation of A-plane and $\mathrm{BO}_{2}$ edge-shared octahedral layers. Therefore, it is expected that this material has the thermoelectric performance similar to $\mathrm{Ca}_{3} \mathrm{Co}_{4} \mathrm{O}_{9}$ or $\mathrm{Na}_{x} \mathrm{CoO}_{2}$.

Many efforts have been made to enhance the thermoelectric properties of delafossite materials in which doping is a popular method. In the family of delafossite materials, $\mathrm{Mg}$-doped $\mathrm{CuCrO}_{2}$ have been known 
as the highest conductivity with a value of $278 \mathrm{~S} / \mathrm{cm}^{6}$ so far. Besides, $\mathrm{Mg}$-doped $\mathrm{CuCrO}_{2}$ also has a high Seebeck coefficient with the value in the range from $200-450 \mu \mathrm{V} / \mathrm{K}^{7-10}$. However, this material encounters with the difficulty that the $\mathrm{Mg}$ doping could significantly improve electrical conductivity, whereas this gives rise to the dramatical decrease of the Seebeck coefficient ${ }^{10,11}$ and causes the increase of the thermal conductivity ${ }^{11}$. For example, Okuda et al. ${ }^{10}$ prepared $\mathrm{CuCr}_{1-x} \mathrm{Mg}_{x} \mathrm{O}_{2}$ compounds with various $\mathrm{Mg}$ concentrations $(0 \leq \mathrm{x} \leq 0.04)$ and found out a dramatic decrease of Seebeck coefficient from 350 to $70 \mu \mathrm{V} / \mathrm{K}$ with a small increase of $\mathrm{Mg}$ concentration from $\mathrm{x}=0$ to 0.03 , respectively. In another report, Hayashi et al. ${ }^{11}$ found out an increase of thermal conductivity from $\sim 6$ to $\sim 7 \mathrm{~W} / \mathrm{m} . \mathrm{K}$ of $\mathrm{CuCr}_{0.97-x} \mathrm{Mg}_{0.03} \mathrm{Ni}_{x} \mathrm{O}_{2}$ compounds as $\mathrm{x}$ increase from 0 to 0.05 , respectively. In the previous report ${ }^{12}$, we systematically investigated the $\mathrm{CuCr}_{1-x} \mathrm{Mg}_{x} \mathrm{O}_{2}(0$ $\leq \mathrm{x} \leq 0.3$ ) compounds. We found out that the high $\mathrm{Mg}$ doping concentration $(\mathrm{x}=0.15)$ could significantly increase the electrical conductivity and decrease the thermal conductivity due to the appearance of the multi-scale defects (copper vacancies, oxygen interstitial, secondary phases like $\mathrm{CuO}, \mathrm{MgCr}_{2} \mathrm{O}_{4}$ ) in the compound.

The solid-state reaction method is commonly used to synthesis the bulk $\mathrm{Mg}$-doped $\mathrm{CuCrO}_{2}$ materials due to its simplification and the ability to build largescale production. The reports related to $\mathrm{Mg}$-doped $\mathrm{CuCrO}_{2}$ compounds used for thermoelectric applications using the conventional solid-state reaction method almost sintered the pellets for a long time of

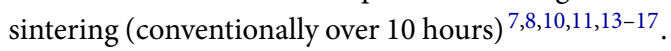
In the industry, reducing the time to make a product is very important to low the cost. In this work, we investigate the effects of the sintering time on thermoelectric properties of $\mathrm{CuCr}_{0.85} \mathrm{Mg}_{0.15} \mathrm{O}_{2}$ compounds to consider the long sintering time as previously reported literature whether it is important or not for this compound.

\section{METHODS}

The $\mathrm{CuCr}_{0.85} \mathrm{Mg}_{0.15} \mathrm{O}_{2}$ bulk samples were prepared by using the conventional solid-state reaction method. $\mathrm{Cu}_{2} \mathrm{O}, \mathrm{Cr}_{2} \mathrm{O}_{3}$, and $\mathrm{MgO}$ powders (the purity $>99 \%$ for all) were used as precursor materials. These materials are mixed by distilled water and ground by a planetary ball mill for grinding the mixed powder in alumina oxide $\left(\mathrm{Al}_{2} \mathrm{O}_{3}\right)$ mortar for 5 hours. The mixture obtained after the grinding process was put into the oven with a temperature of $120^{\circ} \mathrm{C}$ for 24 hours to evaporate the water. After drying, the powder will be ground by hand with an agate mortar and then pressed to form a rectangular shape with a size of $30 \times 30 \times 6 \mathrm{~mm}^{3}$. This green compact will be sintered at $1200^{\circ} \mathrm{C}$ with sintering times of 3 hours and 12 hours. The compounds' crystal structure was investigated using powder $\mathrm{x}$-ray diffraction (XRD) method on the Bruker D8 Advanced system. A small specimen was extracted from the rectangular pellets and was ground by hand on an agate mortar. A 200-mesh sieve filtered the powder to obtain the particle whose diameter is smaller than 74 microns. The interval step of XRD is $0.02^{\circ}$, and the period for a data point is 0.25 seconds. The morphology of a crystal grain was imaged by Field Emission Scanning Electron Microscopy (FESEM) (Hitachi S-4800) from a surface of a specimen broken from the pellets. The phases of bulk samples were detected by using a JEM2100F high-resolution transmission electron microscope (HRTEM). X-ray photoelectron spectroscopy (XPS) was conducted to investigate the chemical state of the compound by using the K-alpha XPS system (Thermo Scientific) with monochromatic $\mathrm{Al} \mathrm{K} \alpha-1486.6 \mathrm{eV}$. The roomtemperature Hall effect based on the Van der Pauw method was used to determine the carrier concentration, hole mobility, and conductivity of the sheet with the dimension of $10 \times 10 \times 0.5 \mathrm{~mm}^{3}$, which was cut from the initial rectangular pellets. The Seebeck coefficient and electrical conductivity were obtained from the LSR-3 system (Linseis GmbH, Germany) in the temperature range of $50-500^{\circ} \mathrm{C}$. An LFA- $457 \mathrm{Mi}$ croFlash Thermal Analyzer (NETZSCH, Germany) was used to determine the total thermal conductivity.

\section{RESULTS AND DISCUSSIONS}

Figure 1 depicts the XRD diagrams of $\mathrm{CuCr}_{0.85} \mathrm{Mg}_{0.15} \mathrm{O}_{2}$ compounds prepared at the sintering temperature of $1200^{\circ} \mathrm{C}$ with the sintering times of 3 and 12 hours. Generally, there is seemingly no significant difference between two XRD patterns which mainly appear in the peaks of the delafossite phase (PDF \# 74-0983). Besides, $\mathrm{MgCr}_{2} \mathrm{O}_{4}$ and $\mathrm{CuO}$ phase were also revealed based on the XRD standards: PDF \#77 - 0007 and \#45 - 0937, respectively. There is no trace of the raw materials, including $\mathrm{Cu}_{2} \mathrm{O}$, $\mathrm{Cr}_{2} \mathrm{O}_{3}$ and $\mathrm{MgO}$ in the XRD patterns, indicating that the compounds were completely converted into $\mathrm{CuCrO}_{2}, \mathrm{MgCr}_{2} \mathrm{O}_{4}$, and $\mathrm{CuO}$ phase at the sintering temperature of $1200{ }^{\circ} \mathrm{C}$. In the literatures, $\mathrm{CuCrO}_{2}$ material is proved that this compound is successfully formed at the sintering temperature more fabulous than $1000{ }^{\circ} \mathrm{C}$ from the raw materials of $\mathrm{Cu}_{2} \mathrm{O}$ and 
$\mathrm{Cr}_{2} \mathrm{O}_{3}{ }^{7,15,17,18}$. The formation of $\mathrm{MgCr}_{2} \mathrm{O}_{4}$ phase in the compounds relates to the solubility of $\mathrm{Mg}$ concentration in $\mathrm{CuCrO}_{2}$ material, which has a low limited solubility under $1 \%{ }^{8,19}$. In this work, the un-stoichiometry of $\mathrm{Cu}$ : $\mathrm{Cr}$ ratio $(1: 0.85)$ of the samples compared with an ideal delafossite material gives rise to the the $\mathrm{CuO}$ phase.

To shed more light on the effects of sintering temperature on structural properties of $\mathrm{CuCr}_{0.85} \mathrm{Mg}_{0.15} \mathrm{O}_{2}$ samples, the $a$ and $c$ lattice parameters of $\mathrm{CuCrO}_{2}$ phase, the crystallite size $\left(D_{h k l}\right.$, where $h k l$ is the Miller indices) of (006), (311), and (111) planes which represent for $\mathrm{CuCrO}_{2}, \mathrm{MgCr}_{2} \mathrm{O}_{4}$, and $\mathrm{CuO}$, respectively, are obtained from XRD data and listed in Table 1. In addition, the mass density is also attached in Table 1. The $a$ and $c$ lattice parameters have an insignificant change for the increase of sintering time, while the crystallite size of all phases has a noticeable change. Specifically, the crystallite size of $D_{006}$ and $D_{111}$ increase approximately 23 and $35 \%$, respectively, while that of $D_{311}$ decreases around $16 \%$ for the increase of sintering time from 3 to 12 hours. Therefore, at a similar sintering temperature, the increase of sintering time prefers to the growth of the crystallite size of the $\mathrm{CuCrO}_{2}$ and $\mathrm{CuO}$ phas. In contrast, $\mathrm{MgCr}_{2} \mathrm{O}_{4}$ phase is inhibited to growth in the crystallite size. This explains why most of reports related to delafossite materials using solid-state reaction method use a long period of sintering time (longer than 10 hours) to optimize the crystal quality 7,8,16,17,21,22. Moreover, the increase of crystallite size of $\mathrm{CuCrO}_{2}$ and $\mathrm{CuO}$ phase and the decrease of that of $\mathrm{MgCr}_{2} \mathrm{O}_{4}$ phase gives rise to the rise of the mass density because the two former phases have higher mass density than the latter one ${ }^{12}$. HRTEM micrographs of $\mathrm{CuCr}_{0.85} \mathrm{Mg}_{0.15} \mathrm{O}_{2}$ compounds, as seen in Figure 2 was used as a supplemental tool for the X-ray diffraction method to detect the existence of the multi-phases in the compounds. The co-existence of $\mathrm{CuCrO}_{2}, \mathrm{MgCr}_{2} \mathrm{O}_{4}$, and $\mathrm{CuO}$ phases in bulk samples is clearly observed regardless of the long or short sintering time. In addition, interplanar spacing between crystal planes of those phases has a reducing trend which implies that the compound become more denser as increasing the sintering time. This result shows the consistent increase of mass density and the sintering time as seen in Table 1 .

The surface morphology of the $\mathrm{CuCr}_{0.85} \mathrm{Mg}_{0.15} \mathrm{O}_{2}$ compounds sintered for different dwell times can be observed in Figure 3. In both images, the $\mathrm{CuCrO}_{2}$ phase can clearly be observed via the grains with the face like "terraces" because the delafossite material has the layer structure ${ }^{23-25}$. Besides, for the sample prepared with low dwell time, grains with the shape of the octahedron (typical shape of spinel $\mathrm{MgCr}_{2} \mathrm{O}_{4}$ ) can be distinctly observed and evenly distributed in the compound, while the octahedral grains are difficult to find in the image of the sample with high dwell time. It is difficult to observe the existence of the $\mathrm{CuO}$ phase by FESEM images due to small contributions, as seen in XRD results. Therefore, from FESEM images, it can be clearly seen the predominance of delafossite phase in the compounds which is the consistence of XRD results.

The $\mathrm{Cu} 2 \mathrm{p}$ photoelectron spectra of the $\mathrm{CuCr}_{0.85} \mathrm{Mg}_{0.15} \mathrm{O}_{2}$ compounds and its $\mathrm{Cu} 2 \mathrm{p}_{3 / 2}$ deconvoluted spectra are shown in Figure 4. The XPS spectra of $\mathrm{Cu} 2 \mathrm{p}$ in Figure 4(a) show an insignificant difference between the compounds and witness the simultaneous existence of $\mathrm{Cu}^{+}$and $\mathrm{Cu}^{2+}$ ion states. Besides, the appearance of a broadband located at ca. 940 - $945 \mathrm{eV}$ and ca. 960 - $965 \mathrm{eV}$ named "satellite" peaks indicates the contribution of the $\mathrm{Cu}^{2+}$ ion state $^{26}$. The blue dash circle in Figure 4(a) indicates that the $\mathrm{Cu}^{2+}$ state tends to increase with sintering time. To get more information on the change of the $\mathrm{Cu}^{2+}$ state, the $\mathrm{Cu} 2 \mathrm{p}_{3 / 2}$ was deconvoluted into two peaks of $\mathrm{Cu}^{+}$and $\mathrm{Cu}^{2+}$ as seen in Figure 4 (b) and (c), respectively. The area percentage of $\mathrm{Cu}^{+}$state has a reducing trend with the increase of sintering time, while $\mathrm{Cu}^{2+}$ has the opposite trend. The mixed-valence states $\mathrm{Cu}^{+} / \mathrm{Cu}^{2+}$ relates to the electrical transport mechanism in $\mathrm{Cu}$-based materials ${ }^{27}$. As listed in Table 2 , the $\mathrm{Cu}^{+} / \mathrm{Cu}^{2+}$ ratio has a reduced trend with the increase of sintering time, which indicates that the electrical transport mechanism depends on this ratio in this work, which means that the conduction occurs by small polaron hopping via the mixed-valence state $\mathrm{Cu}^{+} / \mathrm{Cu}^{2+}$.

Figure 5 depicts the dependence of $\mathrm{Cr}^{3+} 2 \mathrm{p}$ ion state of $\mathrm{CuCr}_{0.85} \mathrm{Mg}_{0.15} \mathrm{O}_{2}$ compounds on the sintering time. There is no difference between the line of two samples, which indicates that the sintering time does not give rise to the change in the $\mathrm{Cr}^{3+}$ ion state. Besides, the appearance of $\mathrm{Cu} \mathrm{L}_{3} \mathrm{M}_{45} \mathrm{M}_{45}$ at the binding energy of $569.2 \mathrm{eV}$ indicates that the delafossite phase is contaminated by copper oxide ${ }^{28}$.

In comparison with XPS spectra of $\mathrm{Cu} 2 \mathrm{p}$ and $\mathrm{Cr} 2 \mathrm{p}$, the XPS spectra of O 1s shown in Figure 6(a) has a significant difference between two sintering time. To get more detailed information, the XPS spectra of $\mathrm{O} 1 \mathrm{~s}$ were deconvoluted into three peaks: $\left(\mathrm{O}_{i}\right)$ is assigned to the oxygen in its position of crystal structure which bonds with metal atoms, $\left(\mathrm{O}_{i i}\right)$ relates to the intercalation of oxygen between the $\mathrm{Cu}$-plane and $\mathrm{CrO}_{6}$ plane in delafossite structure, and $\left(\mathrm{O}_{i i i}\right)$ is surface absorbed oxygen $^{22,29,30}$. The deconvoluted results are shown 


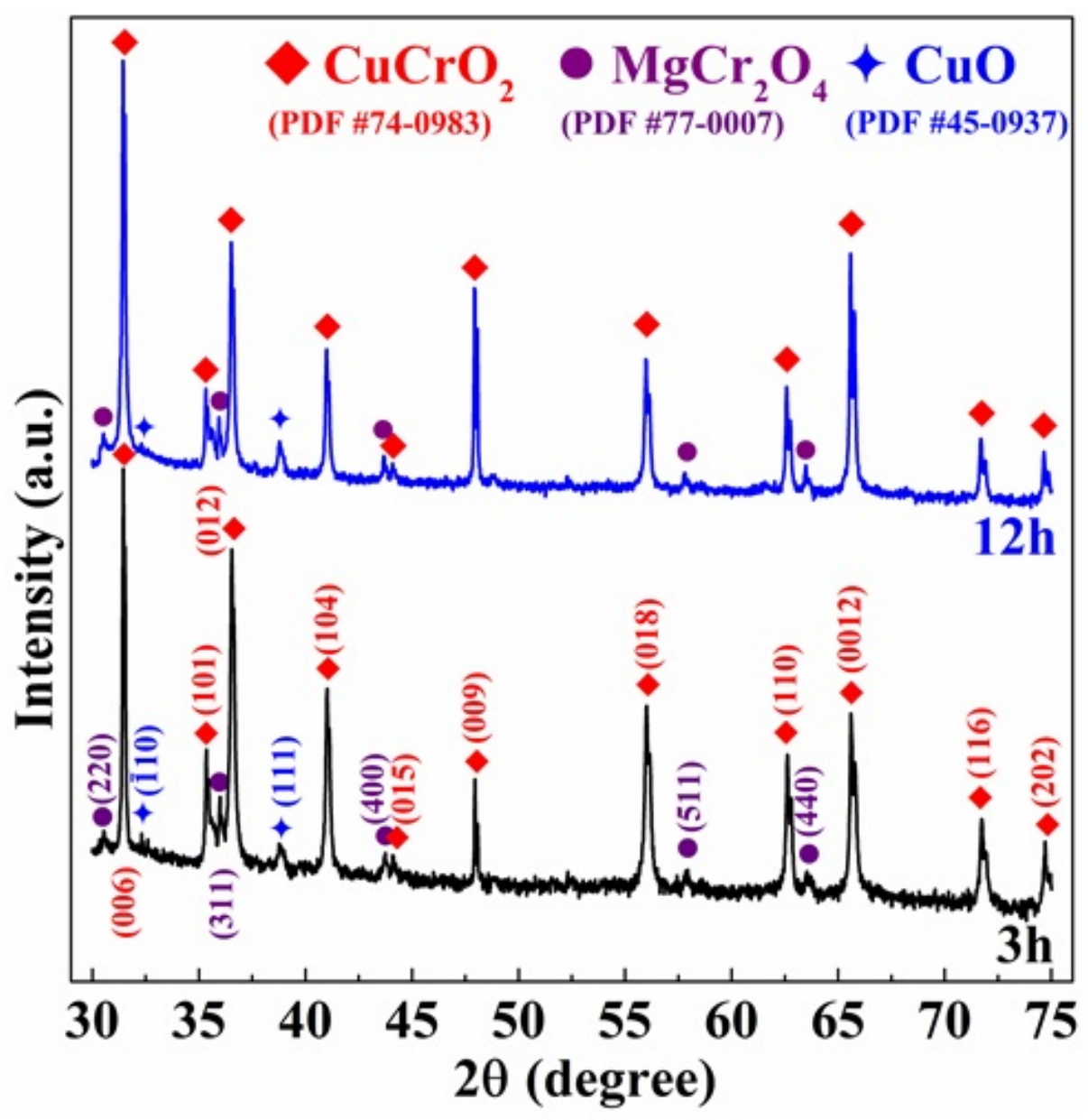

Figure 1: XRD patterns of $\mathrm{CuCr}_{0.85} \mathrm{Mg}_{0.15} \mathrm{O}_{2}$ samples prepared at two different sintering time. The $\mathrm{CuCrO}_{2}, \mathrm{CuO}$ and $\mathrm{MgCr}_{2} \mathrm{O}_{4}$ phases are symbolled by the red rhombus, blue four-sided star and purple circle based on the PDF files: \# 74-0983, \# 45-0937 and \# 77-0007, respectively. XRD pattern of 3h sample was reprinted from the Ref. ${ }^{20}$.

Table 1: Structural parameters extracted from XRD results. The $a$ and $c$ lattice parameters are derived from (110) and (006) plane of $\mathrm{CuCrO}_{2}$ phase, respectively. The crystallite size calculated from (006), (311) and (111) plane based on Scherrer equation respectively represents $\mathrm{CuCrO}_{2}, \mathrm{MgCr}_{2} \mathrm{O}_{4}$ and CuO phases.

\begin{tabular}{lll}
\hline Structural parameters & $\mathrm{CuCr}_{0.85} \mathrm{Mg}_{0.15} \mathrm{O}_{2} @ 3 \mathrm{~h}$ & $\mathrm{CuCr}_{0.85} \mathrm{Mg}_{0.15} \mathrm{O}_{2} @ 12 \mathrm{~h}$ \\
$a$ lattice $(\AA)$ & 2.965 & 2.966 \\
$c$ lattice $(\AA)$ & 17.055 & 17.054 \\
$(006)$ crystallite size $(\mathrm{nm})\left[\mathrm{CuCrO}_{2}\right]$ & 166 & 205 \\
$(311)$ crystallite size $(\mathrm{nm})\left[\mathrm{MgCr}_{2} \mathrm{O}_{4}\right]$ & 109 & 92 \\
$(111)$ crystallite size $(\mathrm{nm})[\mathrm{CuO}]$ & 31 & 42 \\
Mass density $\left(\mathrm{g} / \mathrm{cm}^{3}\right)$ & 3.71 & 3.91 \\
\hline
\end{tabular}



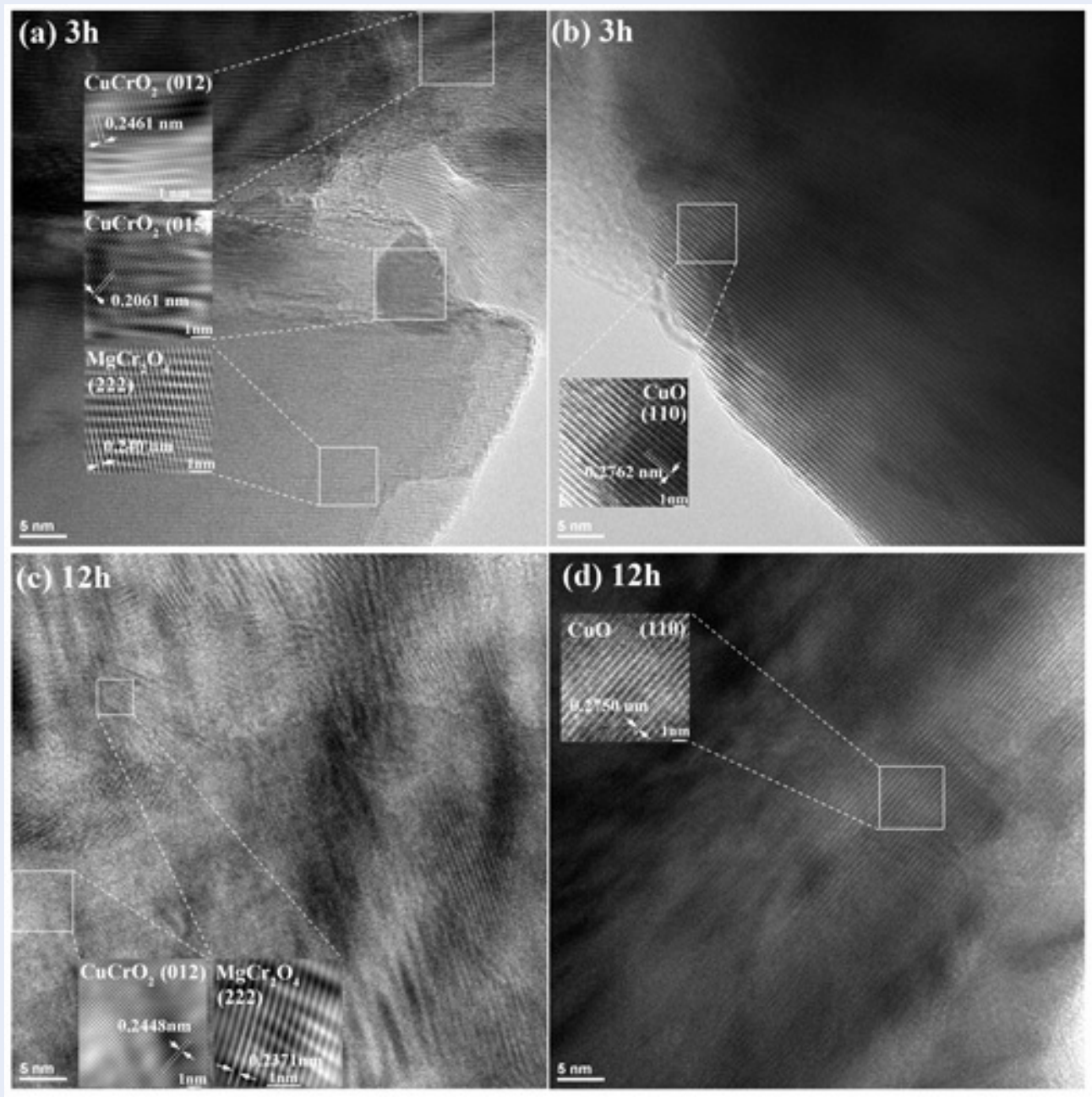

Figure 2: HRTEM images of $\mathrm{CuCr}_{0.85} \mathrm{Mg}_{0.15} \mathrm{O}_{2}$ compounds sintered at sintering time of $(\mathrm{a}, \mathrm{b}) 3$ hours and $(c, d) 12$ hours.

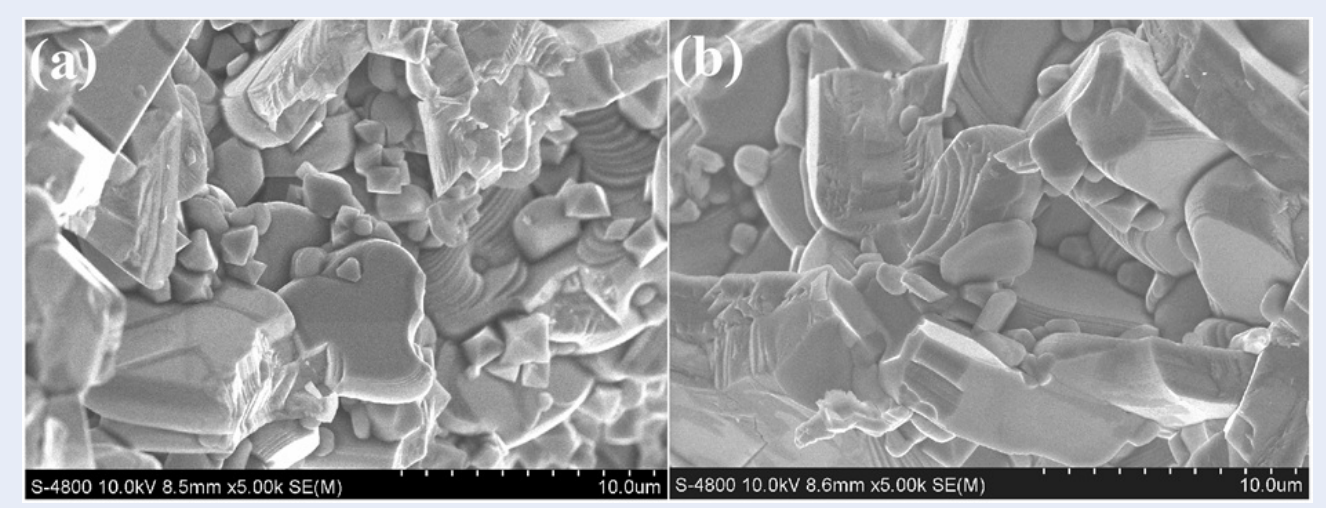

Figure 3: FESEM images of $\mathrm{CuCr}_{0.85} \mathrm{Mg}_{0.15} \mathrm{O}_{2}$ compounds prepared at $1200{ }^{\circ} \mathrm{C}$ with the sintering time of (a) 3 hours and (b) 12 hours. FESEM image of $3 \mathrm{~h}$ sample was reprinted from the Ref. ${ }^{20}$. 


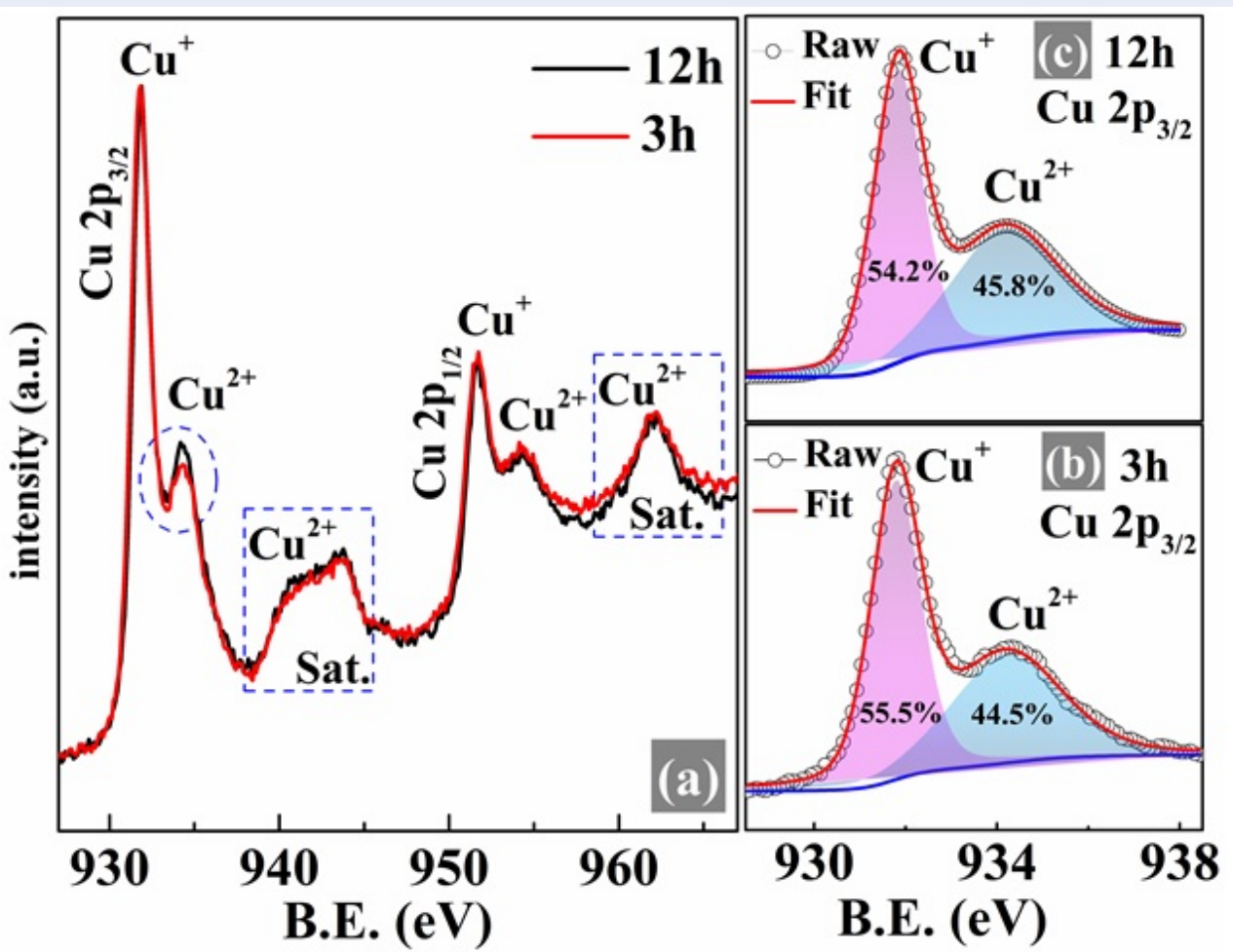

Figure 4: XPS curves of (a) $\mathrm{Cu} 2 \mathrm{p}$ of $\mathrm{CuCr}_{0.85} \mathrm{Mg}_{0.15} \mathrm{O}_{2}$ compounds prepared at various sintering times. Deconvoluted XPS spectra of $\mathrm{Cu} 2 \mathrm{p}_{3 / 2}$ of (b) $3 \mathrm{~h}$ and (c) $12 \mathrm{~h}$ samples. The dash blue circle and rectangular depict the region of the $\mathrm{Cu}^{2+}$ state in the $\mathrm{Cu} 2 \mathrm{p} 3 / 2$ peak and the satellite (sat.) peaks. XPS results of $3 \mathrm{~h}$ sample were reprinted from Ref. $^{20}$.

in Figure 6(b) and (c), and their details are listed in Table 2 below. The increase of sintering time gives rise to a decrease in $\mathrm{O}_{i i}$ and $\mathrm{O}_{i i i}$, while the percentage of $\mathrm{O}_{i}$ has the opposite trend. The increase of the percentage of $\mathrm{O}_{i}$ with an approximate ratio of $13.4 \%$ indicates that the crystal structure is significantly improved, which is consistent with XRD results. In comparison, the percentage of $\mathrm{O}_{i i}$ decreases by about 2.7 $\%$, which implies that the increase of sintering time causes $\mathrm{O}_{i i}$ to move into oxygen vacancies and become $\mathrm{O}_{i}$. Besides, the densification of the compound with the increase of sintering time as seen in Table 1 gives rise to a decrease the percentage of $\mathrm{O}_{i i i}$.

The hole concentration, hole mobility, and conductivity of $\mathrm{CuCr}_{0.85} \mathrm{Mg}_{0.15} \mathrm{O}_{2}$ compounds prepared at the sintering time of 3 and 12 hours are listed in Table 3 . Those values generally increase with the elevation of sintering time from 3 to 12 hours. This enhancement of electrical properties is due to the improvement of crystal structure, and the sites of oxygen vacancies filled up by $\mathrm{O}_{i i}$, as mentioned above.
The electrical conductivity $(\sigma)$, Seebeck coefficient $(\mathrm{S})$, and power factor (PF) of $\mathrm{CuCr}_{0.85} \mathrm{Mg}_{0.15} \mathrm{O}_{2}$ compounds depending on measuring temperature in Figure 7 show a general picture of the effects of sintering time on the electrical properties. The EC in Figure 7 (a) has a slight increase in sintering time and measuring temperature. The increase of $\sigma$ with measuring temperature indicates that the $\sigma$ of the compounds behaves as semiconductors. The elevation of sintering time enhances the $\sigma$ because the oxygen vacancies could be passivated by oxygen $\left(\mathrm{O}_{i i}\right)$. The $\mathrm{S}$ in Figure $7(\mathrm{~b})$ is positive values which indicate that the compounds are $\mathrm{p}$-type semiconductors. The $\mathrm{S}$ values of the compounds have a similar value as the measuring temperature is lower than $300{ }^{\circ} \mathrm{C}$. However, at a high measuring temperature $\left(>300^{\circ} \mathrm{C}\right)$, the $\mathrm{S}$ values of $12 \mathrm{~h}$ sample are higher than that of $3 \mathrm{~h}$ sample. The power factor directly depends on $\sigma$ and $\mathrm{S}$ (i.e., $\mathrm{PF}=$ $\left.\sigma . S^{2}\right)$, and hence, in Figure 7(c), the PF values of $12 \mathrm{~h}$ sample are higher than that of $3 \mathrm{~h}$ sample because of electrical conductivity. 


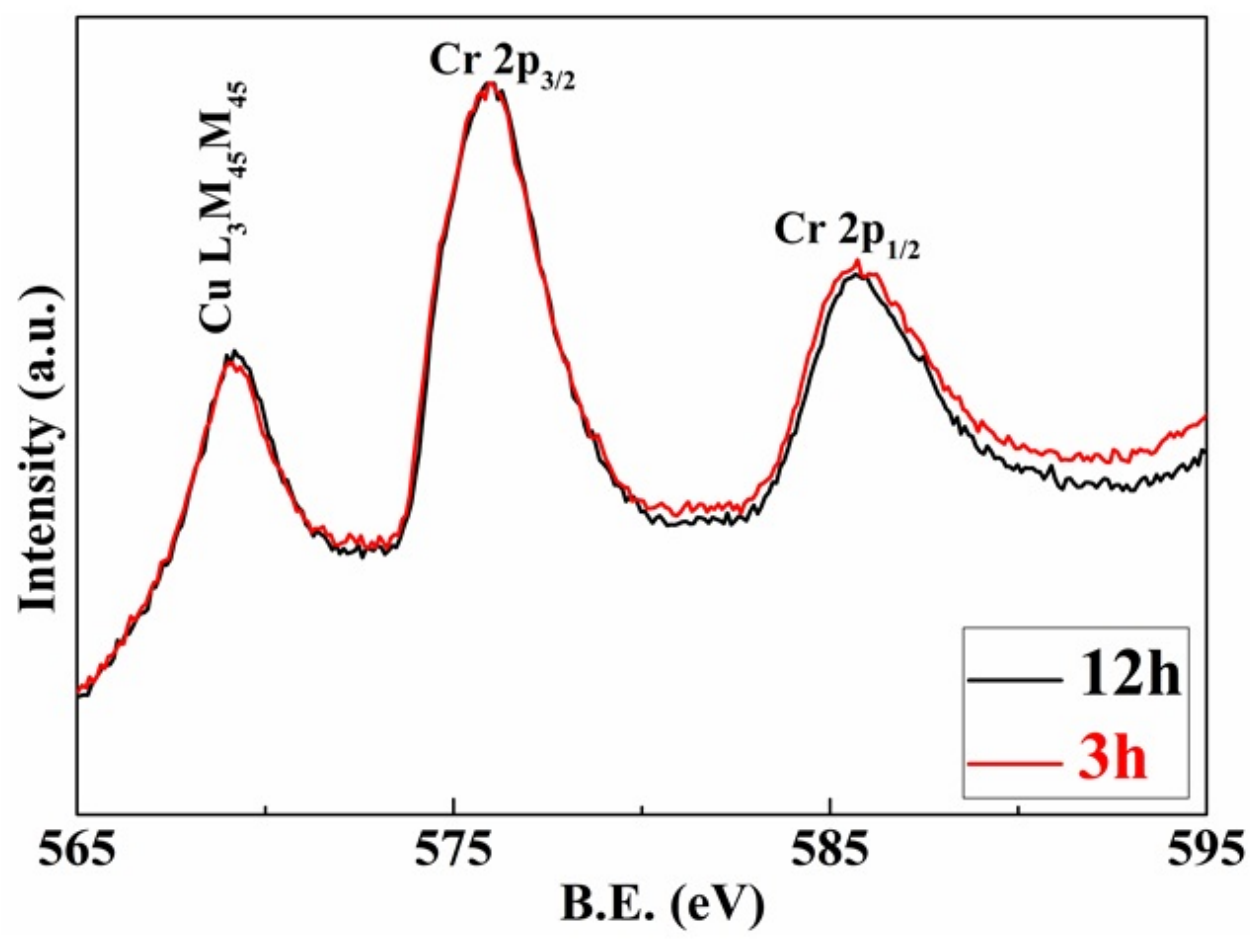

Figure 5: XPS spectra of $\mathrm{Cr} 2 \mathrm{p}$ of $\mathrm{CuCr}_{0.85} \mathrm{Mg}_{0.15} \mathrm{O}_{2}$ compounds prepared at various sintering times. XPS results of 3h sample were reprinted from Ref. ${ }^{20}$.

Table 2: Binding energy (B.E.), fullwidth at half maximum (FWHM), and area percentage (\%) of $\mathrm{Cu} 2 \mathrm{p}_{3 / 2}$, and $01 \mathrm{~s}$ peaks extracted from XPS spectra by deconvoluting based on Gaussian - Lorentzian mixed function. The area ratio of $\left[\mathrm{Cu}^{+/ 2+}\right]$ was calculated by using the area of each peak.

\begin{tabular}{|c|c|c|c|c|c|c|}
\hline & \multicolumn{3}{|c|}{$3 \mathrm{~h}$} & \multicolumn{3}{|c|}{$12 \mathrm{~h}$} \\
\hline & $\begin{array}{l}\text { B.E. } \\
(\mathrm{eV})\end{array}$ & $\begin{array}{l}\text { FWHM } \\
(\mathrm{eV})\end{array}$ & $\%$ & $\begin{array}{l}\text { B.E. } \\
(\mathrm{eV})\end{array}$ & $\begin{array}{l}\text { FWHM } \\
(\mathrm{eV})\end{array}$ & $\%$ \\
\hline \multirow[t]{2}{*}{$\begin{array}{l}\mathrm{Cu} \\
2 \mathrm{p}_{3 / 2}\end{array}$} & $\begin{array}{l}931.8 \\
{\left[\mathrm{Cu}^{+}\right]}\end{array}$ & 1.3 & 55.5 & 931.8 & 1.3 & 54.2 \\
\hline & $\begin{array}{l}934.2 \\
{\left[\mathrm{Cu}^{2+}\right]}\end{array}$ & 2.9 & 44.5 & 934.2 & 2.7 & 45.8 \\
\hline$\left[\mathrm{Cu}^{+} /^{2+}\right]$ & \multicolumn{3}{|c|}{1.25} & \multicolumn{3}{|c|}{1.19} \\
\hline O 1s & $\begin{array}{l}529.5 \\
\text { (i) }\end{array}$ & 1.1 & 36.5 & 529.5 & 1.1 & 41.4 \\
\hline & $\begin{array}{l}531.1 \\
\text { (ii) }\end{array}$ & 1.8 & 55.2 & 531.1 & 1.5 & 53.7 \\
\hline & $\begin{array}{l}532.5 \\
\text { (iii) }\end{array}$ & 2.1 & 8.3 & 532.5 & 2.1 & 4.9 \\
\hline
\end{tabular}




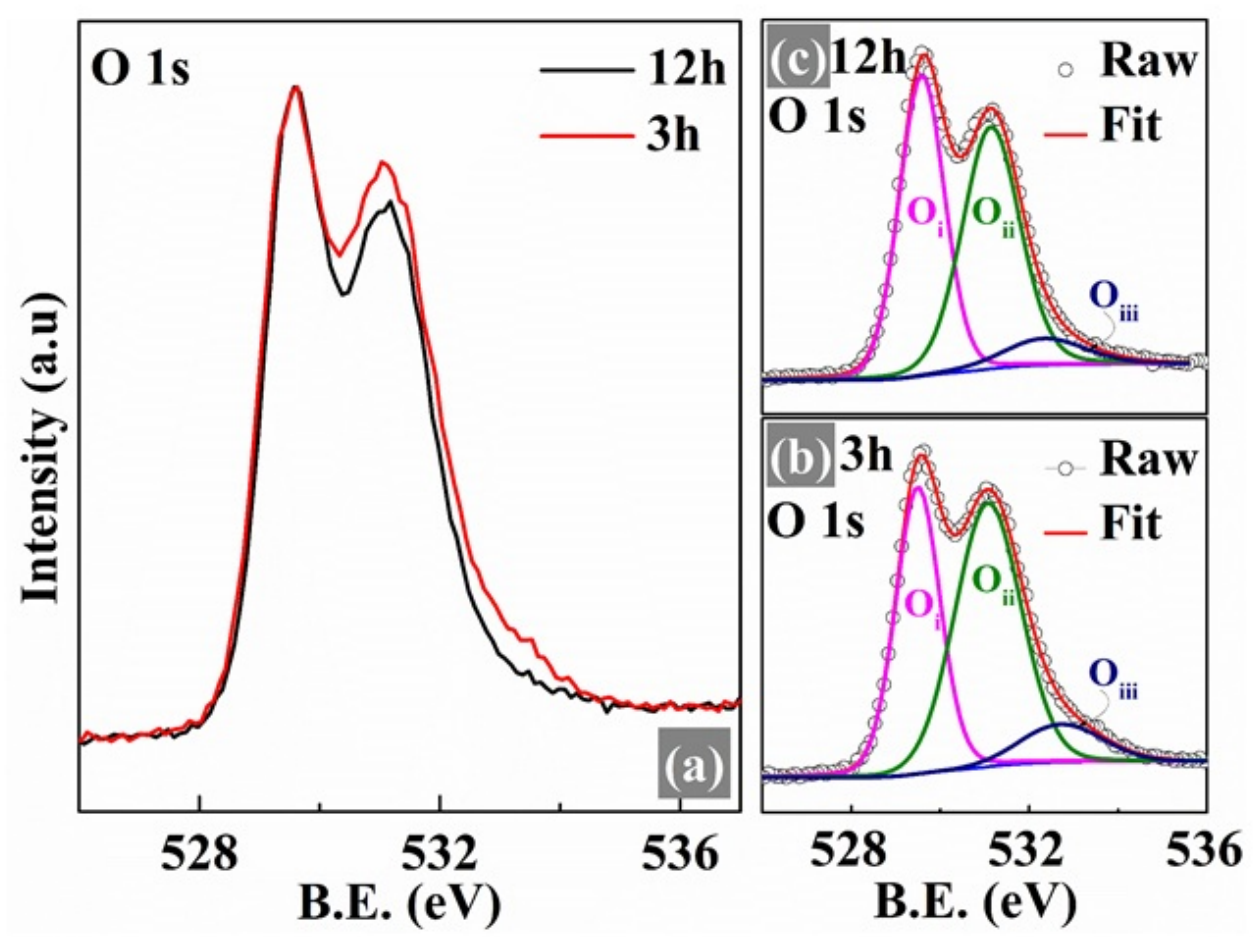

Figure 6: XPS spectra of (a) $\mathrm{O} 1 \mathrm{~s}$ of $\mathrm{CuCr}_{0.85} \mathrm{Mg}_{0.15} \mathrm{O}_{2}$ compounds prepared at various sintering times. Deconvoluted XPS spectra of $\mathrm{O} 1 \mathrm{~s}$ of (b) $3 \mathrm{~h}$ and (b) $12 \mathrm{~h}$ samples. XPS results of $3 \mathrm{~h}$ sample were reprinted from Ref. ${ }^{20}$.

Table 3: The room temperature hole concentration, hole mobility, and conductivity of $\mathrm{CuCr}_{0.85} \mathbf{M g}_{0.15} \mathbf{O}_{2}$ compounds prepared at various sintering times. Hall measurement results of $3 \mathrm{~h}$ sample were reprinted from Ref. ${ }^{20}$.

\begin{tabular}{llll}
\hline Sample & $\begin{array}{l}\text { Hole concentration } \\
\left(\times 1019 \mathrm{~cm}^{-3}\right)\end{array}$ & $\begin{array}{l}\text { Hole mobility } \\
\left(\mathrm{cm}^{2} / \mathrm{Vs}\right)\end{array}$ & $\begin{array}{l}\text { Conductivity } \\
(\mathrm{S} / \mathrm{cm})\end{array}$ \\
$\begin{array}{l}\mathrm{CuCr}_{0.85} \mathrm{Mg}_{0.15} \mathrm{O}_{2} \\
@ 3 \mathrm{~h}\end{array}$ & 3.9 & 0.49 & 3.1 \\
$\begin{array}{l}\mathrm{CuCr} \\
\text { @ } 12 \mathrm{~h}\end{array}$ & 5.3 & 0.55 & 4.7 \\
\hline
\end{tabular}

Figure 8 shows the correlation between the electron $\left(\kappa_{e}\right)$, lattice $\left(\kappa_{\text {lat }}\right)$, and total thermal conductivity $\left(\kappa_{\text {tot. }}\right)$ and measuring the temperature of $\mathrm{CuCr}_{0.85} \mathrm{Mg}_{0.15} \mathrm{O}_{2}$ compounds prepared at sintering time of $3 \mathrm{~h}$ and $12 \mathrm{~h}$. Figure 8(a) shows that the electron thermal conductivity exhibits a small increase with the sintering time, but its contribution to the total thermal conductivity is insignificant. The lineshape of $\kappa_{l a t}$. and $\kappa_{t o t}$. match well together, which indicates that the $\kappa_{t o t}$. is mainly governed by the $\kappa_{\text {lat. }}$. The $\kappa_{t o t}$. increases approximately $10 \%$ with the rise of sintering time from 3 hours to 12 hours. The increase of $\kappa_{\text {tot }}$. relates to the change of crystallite size of $\mathrm{CuCrO}_{2}$ and $\mathrm{MgCr}_{2} \mathrm{O}_{4}$ phases. More specifically,
$\mathrm{CuCrO}_{2}$ phase has high thermal conductivity $(5-10$ $\mathrm{W} / \mathrm{mK})^{11,24}$, while $\mathrm{MgCr}_{2} \mathrm{O}_{4}$ phase has relatively low thermal conductivity $(\sim 2 \mathrm{~W} / \mathrm{mK})^{12,31}$. Therefore, the increase and decrease of crystallite size of $\mathrm{CuCrO}_{2}$ and $\mathrm{MgCr}_{2} \mathrm{O}_{4}$ phase, respectively, give rise to the increase of the $\kappa_{\text {tot }}$.

There is a slight increase of PF, as seen in Figure 7 along with the rise of sintering time. Still, the thermal conductivity shown in Figure 8 also increases, which gives rise to the almost unchanged $\mathrm{ZT}$ values despite a fourfold increase of the sintering time as depicted in Figure 9. The thermal conductivity is almost constant with the measuring temperature, and therefore the rise of $\mathrm{ZT}$ is dependent on electrical conductivity. The compounds reach the highest $\mathrm{ZT}$ value of 3 

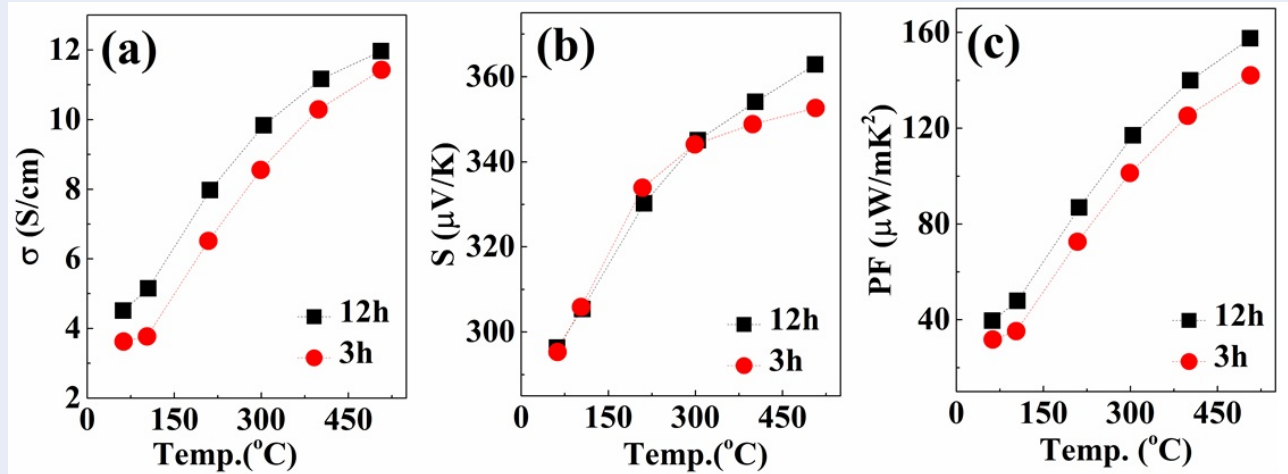

Figure 7: Thermoelectric properties of of $\mathrm{CuCr}_{0.85} \mathrm{Mg}_{0.15} \mathrm{O}_{2}$ compounds. (a) The electrical conductivity, (b) Seebeck coefficient, and (c) power factor of samples prepared at sintering time of $3 \mathrm{~h}$ and $12 \mathrm{~h}$ as a function of measuring temperature. The electrical conductivity, Seebeck coefficient, and power factor results of $3 \mathrm{~h}$ sample was reprinted from Ref. $^{20}$.
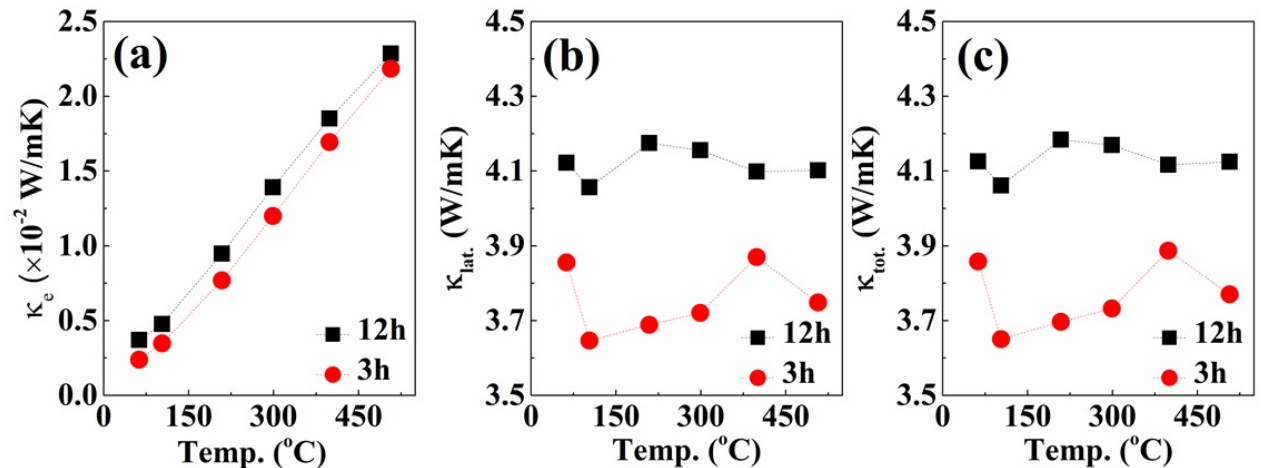

Figure 8: Temperature dependence of (a) the electrical, (b) the lattice, and (c) total thermal conductivity of $\mathrm{CuCr}_{0.85} \mathrm{Mg}_{0.15} \mathrm{O}_{2}$ compounds prepared at sintering time of $3 \mathrm{~h}$ and $12 \mathrm{~h}$.

$\times 10^{-2}$ at the measuring temperature of $500{ }^{\circ} \mathrm{C}$ regardless of the short or long period of the sintering time. This value of ZT is relatively high compared to published reports related to doped $\mathrm{CuCrO}_{2}{ }^{32}$ or other cuprous delafossite materials ${ }^{22}$ at a similar measuring temperature.

\section{CONCLUSIONS}

The effects of the sintering time on the crystal structure, the chemical state, and the thermoelectric properties of $\mathrm{CuCr}_{0.85} \mathrm{Mg}_{0.15} \mathrm{O}_{2}$ compounds prepared at a sintering temperature of $1200^{\circ} \mathrm{C}$ have been investigated in this work. The $\mathrm{XRD}$ results show an increase of crystallite size of $\mathrm{CuCrO}_{2}$ and $\mathrm{CuO}$ phase. In contrast, the crystallite size of the $\mathrm{MgCr}_{2} \mathrm{O}_{4}$ phase shows the reducing tendency, which gives rise to the increase of total thermal conductivity. However, the $\mathrm{ZT}$ value is almost constant due to the rise of electrical conductivity. Generally, based on ZT results, it is observed that in the case of $\mathrm{CuCr}_{0.85} \mathrm{Mg}_{0.15} \mathrm{O}_{2}$ compounds, the short sintering time (3 hours) is enough for synthesizing materials used for thermoelectric applications, which in turn increase the economic performance.

\section{LIST OF ABBREVIATIONS}

ZT: dimensionless figure of merit

XRD: powder X-ray diffraction

FESEM: Field Emission Scanning Electron $\mathrm{Mi}$ croscopy

HRTEM: high-resolution transmission electron microscope

XPS: X-ray photoelectron spectroscopy

B.E.: Binding energy

FWHM: fullwidth at half maximum 


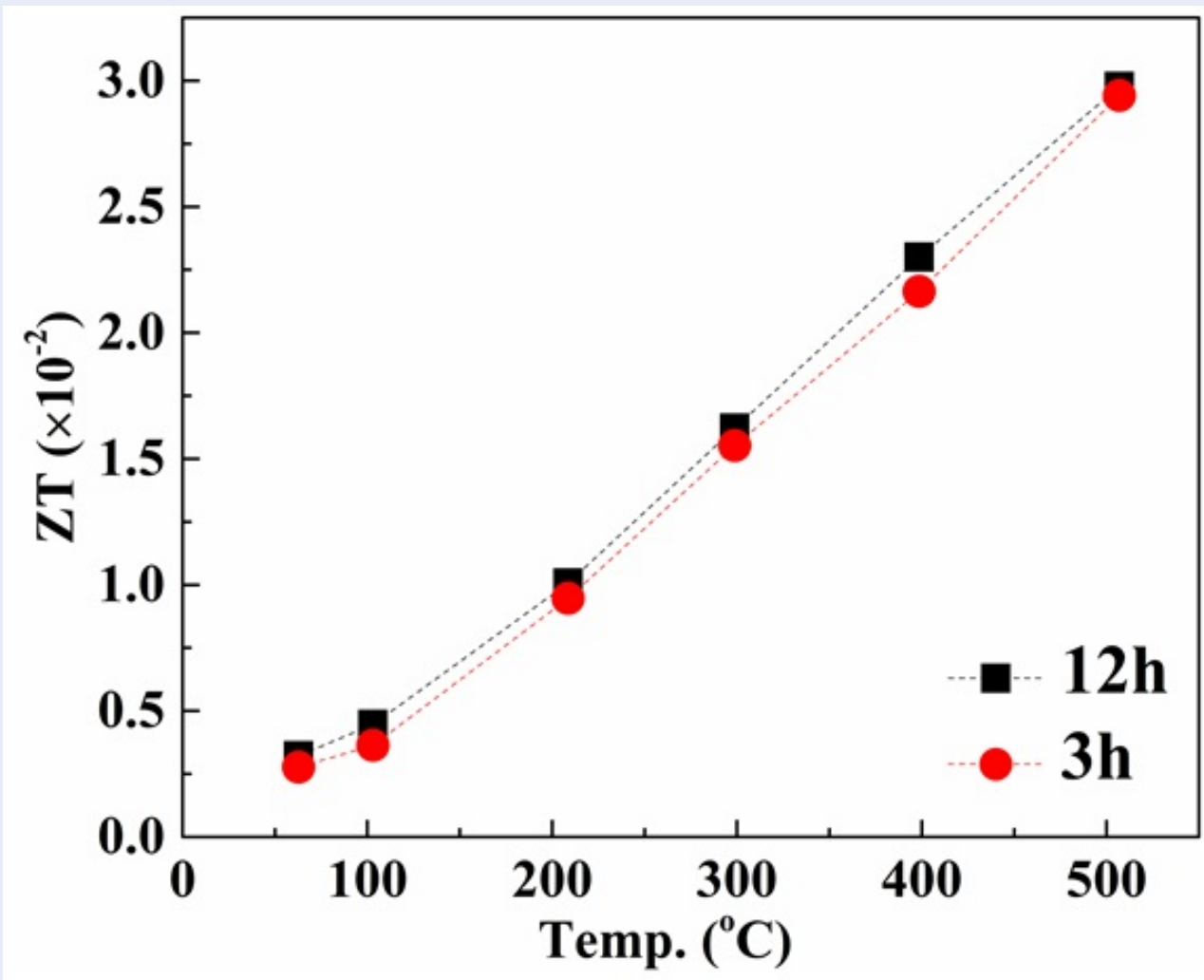

Figure 9: Temperature dependence of the dimensionless figure of merit ( $\mathrm{ZT}$ ) of $\mathrm{CuCr}_{0.85} \mathrm{Mg}_{0.15} \mathrm{O}_{2}$ compounds prepared at different sintering times.

PDF: Powder diffraction file

\section{AUTHORS CONTRIBUTION}

Dung Van Hoang: Data curation, Methodology; Investigation, Writing-original draft; Truong Huu Nguyen: Data curation, Formal Analysis; Anh Tuan Thanh Pham: Data curation, Formal Analysis; Thu Bao Nguyen Le: Data curation, Formal Analysis; Vinh Cao Tran: Data curation, Supervision; Thang Bach Phan: Conceptualization, Funding acquisition, Methodology, Writing - review \& editing.

\section{CONFLICT OF INTEREST}

The authors declare that they have no competing interests.

\section{ACKNOWLEDGMENTS}

This work was supported by the Vietnam Ministry of Science and Technology under grant number ĐTĐL.CN-23/18.

\section{REFERENCES}

1. Li W, Poudel B, Nozariasbmarz A, Sriramdas R, Zhu H, Kang HB, et al. Bismuth Telluride/Half-Heusler Segmented Thermoelec- tric Unicouple Modules Provide 12\% Conversion Efficiency. Adv Energy Mater. 2020;2001924:1-9;Available from: https:// doi.org/10.1002/aenm.202001924.

2. He J, Liu Y, Funahashi R. Oxide thermoelectrics: The challenges, progress, and outlook. J Mater Res. 2011;26(15):176272;Available from: https://doi.org/10.1557/jmr.2011.108.

3. Prasad R, Bhame SD. Review on texturization effects in thermoelectric oxides. Mater Renew Sustain Energy [Internet]. 2020 Mar 9;9(1):3;Available from: https://doi.org/10.1007/ s40243-019-0163-y.

4. Koumoto K, Wang $Y$, Zhang R, Kosuga A, Funahashi R. Oxide Thermoelectric Materials: A Nanostructuring Approach. Annu Rev Mater Res [Internet]. 2010 Jun;40(1):36394;Available from: http://www.annualreviews.org/doi/10.1146/ annurev-matsci-070909-104521.

5. Torres MA, Mora M, Amaveda H, Madre MA, Sotelo A. Effect of substrate on the microstructure and thermoelectric performances of Sr-doped Ca3Co4O9 thick films. Ceram Int [Internet]. 2019 Apr;45(5):5431-5;Available from: https:// linkinghub.elsevier.com/retrieve/pii/S0272884218333625.

6. Ahmadi M, Asemi M, Ghanaatshoar M. Mg and N co-doped CuCrO 2 : A record breaking p-type TCO. Appl Phys Lett [Internet]. 2018 Dec 10;113(24):242101;Available from: http://aip. scitation.org/doi/10.1063/1.5051730.

7. Manickam R, Biswas K. Double doping induced power factor enhancement in $\mathrm{CuCrO} 2$ for high temperature thermoelectric application. J Alloys Compd [Internet]. 2019 Feb;775:1052-6;Available from: https: //doi.org/10.1016/j.jallcom.2018.10.083. 
8. Guilmeau E, Poienar M, Kremer $\mathrm{S}$, Marinel $\mathrm{S}$, Hébert $\mathrm{S}$, Frésard $\mathrm{R}$, et al. $\mathrm{Mg}$ substitution in $\mathrm{CuCrO} 2$ delafossite compounds. Solid State Commun [Internet]. 2011 Dec;151(23):1798-801;Available from: https: //linkinghub.elsevier.com/retrieve/pii/S0038109811004455.

9. Bywalez R, Götzendörfer S, Löbmann P. Structural and physical effects of Mg-doping on p-type $\mathrm{CuCrO} 2$ and $\mathrm{CuAl0} 0.5 \mathrm{Cr} 0.5 \mathrm{O} 2$ thin films. J Mater Chem. 2010;20(31):6562-70;Available from: https://doi.org/10.1039/b926424h.

10. Okuda T, Jufuku N, Hidaka S, Terada N. Magnetic, transport, and thermoelectric properties of the delafossite oxides $\mathrm{CuCr1}$ xMgxO2 $(0 \leq x \leq 0.04)$. Phys Rev B - Condens Matter Mater Phys. 2005;72(14):4-8;Available from: https://doi.org/10.1103/ PhysRevB.72.144403.

11. Hayashi K, Sato K, Nozaki T, Kajitani T. Effect of Doping on Thermoelectric Properties of Delafossite-Type Oxide $\mathrm{CuCrO} 2$ Jpn J Appl Phys [Internet]. 2008 Jan 18;47(1):59-63;Available from: https://doi.org/10.1143/JJAP.47.59.

12. Van HD, Thanh PAT, Thi THK, Nguyen TH, Pham NK, Hoa LT, et al. Effects of multi-scale defects on the thermoelectric prop-

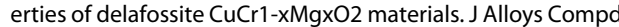
[Internet]. 2020 Dec;844:156119;Available from: https://doi. org/10.1016/j.jallcom.2020.156119.

13. Sakulkalavek A, Sakdanuphab R. Power factor improvement of delafossite $\mathrm{CuAlO} 2$ by liquid-phase sintering with $\mathrm{Ag} 2 \mathrm{O}$ addition. Mater Sci Semicond Process [Internet]. 2016;56(August):313-23;Available from: https://doi.org/10.1016/j.mssp.2016.08.023.

14. Meng Q, Lu SS, Lu SS, Xiang Y. Preparation of p-type $\mathrm{CuCr} 1-\mathrm{xMgxO} 2$ bulk with improved thermoelectric properties by sol-gel method. J Sol-Gel Sci Technol. 2012 Jul;63(1):17;Available from: https://doi.org/10.1007/s10971-012-2732-8.

15. Barot N, Mehta PK, Rao A, Thomas R, Kuo YK. Effects of iso- and polyvalent substitutions on the short/long-range crystalline order in CuCrO2 compounds. J Alloys Compd. 2019;791:13443;Available from: https://doi.org/10.1016/j.jallcom.2019.03. 291.

16. Rudradawong C, Ruttanapun C. Effect of excess oxygen for $\mathrm{CuFeO2.06}$ delafossite on thermoelectric and optical properties. Phys B Condens Matter. 2017;526(September):217;Available from: https://doi.org/10.1016/j.physb.2017.09.046.

17. Jantrasee S, Ruttanapun C. Impact of Sn4+ Substitution at $\mathrm{Cr} 3+$ Sites on Thermoelectric and Electronic Properties of $\mathrm{p}$ Type Delafossite CuCrO2. J Electron Mater. 2020;49(1):60110;Available from: https://doi.org/10.1007/s11664-019-077809.

18. Amrute AP, Łodziana Z, Mondelli C, Krumeich F, PérezRamírez J. Solid-State Chemistry of Cuprous Delafossites: Synthesis and Stability Aspects. Chem Mater [Internet]. 2013 Nov 12;25(21):4423-35;Available from: https://doi.org/ $10.1021 / \mathrm{cm} 402902 \mathrm{~m}$

19. Tripathi TS, Karppinen M. Enhanced p-Type Transparent Semiconducting Characteristics for ALD-Grown Mg-Substituted CuCrO2 Thin Films. Adv Electron Mater [Internet]. 2017 Jun;3(6):1600341;Available from: https://doi.org/10.1002/aelm.201600341.

20. Van HD, Kieu LTA, Pham ATT, Thi THK, Pham NK, Nguyen TH, et al. The roles of interstitial oxygen and phase compositions on the thermoelectric properties $\mathrm{CuCr} 0.85 \mathrm{Mg} 0.15 \mathrm{O} 2$ delafossite material. J Alloys Compd [Internet]. 2021;867:158995;Available from: https://doi.org/10.1016/j.jallcom.2021.158995.

21. Rattanathrum P, Taddee C, Chanlek N, Thongbai P, Kamwanna T. Structural and physical properties of $\mathrm{Ge}$-doped $\mathrm{CuCrO} 2$ delafossite oxide. Ceram Int [Internet]. 2017;43(May):S41722;Available from: https://doi.org/10.1016/j.ceramint.2017.05. 244.

22. Daichakomphu N, Harnwunggmoung A, Chanlek N, Sakdanuphab R, Sakulkalavek A. Figure of merit improvement of delafossite $\mathrm{CuAlO} 2$ with the addition of $\mathrm{Fe}$ and graphene. J Phys Chem Solids [Internet]. 2019 Nov;134(March):2934;Available from: https://doi.org/10.1016/j.jpcs.2019.05.032.

23. Bredar ARC, Blanchet MD, Comes RB, Farnum BH. Evidence and influence of copper vacancies in p-type $\mathrm{CuGaO} 2$ mesoporous films. ACS Appl Energy Mater. 2019;2(1):19 28;Available from: https://doi.org/10.1021/acsaem.8b01558.

24. Ngo TNM, Palstra TTM, Blake GR. Crystallite size dependence of thermoelectric performance of $\mathrm{CuCrO} 2$. RSC Adv [Internet]. 2016;6(94):91171-8;Available from: https://doi.org/10 1039/C6RA08035A.

25. Bolloju S, Srinivasan R. Sub-micron-sized delafossite $\mathrm{CuCrO2}$ with different morphologies synthesized by nitrate-citric acid sol-gel route. Bull Mater Sci. 2017;40(1):195-9;Available from: https://doi.org/10.1007/s12034-016-1340-6.

26. Monteiro JFHL, Monteiro FC, Jurelo AR, Mosca DH. Conductivity in (Ag,Mg)-doped delafossite oxide CuCrO2. Ceram Int. 2018;44(12):14101-7;Available from: https://doi.org/10.1016/j. ceramint.2018.05.008.

27. Barnabé $A$, Thimont $Y$, Lalanne $M$, Presmanes $L$, Tailhades $P$. P-Type conducting transparent characteristics of delafossite Mg-doped $\mathrm{CuCrO} 2$ thin films prepared by RF-sputtering. Mater Chem C. 2015;3(23):6012-24;Available from: https://doi. org/10.1039/C5TC01070E.

28. Crêpellière J, Popa $P L$, Bahlawane $N$, Leturcq $R$, Werner $F$ Siebentritt $\mathrm{S}$, et al. Transparent conductive $\mathrm{CuCrO} 2$ thin films deposited by pulsed injection metal organic chemical vapor deposition: Up-scalable process technology for an improved transparency/conductivity trade-off. J Mater Chem C. 2016;4(19):4278-87;Available from: https://doi.org/10.1039/ C6TC00383D.

29. Lin F, Gao C, Zhou X, Shi W, Liu A. Magnetic, electrical and optical properties of p-type Fe-doped $\mathrm{CuCrO} 2$ semiconductor thin films. J Alloys Compd. 2013;581:502-7;Available from: https://doi.org/10.1016/j.jallcom.2013.07.160.

30. Tong B, Deng Z, Xu B, Meng G, Shao J, Liu H, et al. Oxygen Vacancy Defects Boosted High Performance p-Type Delafossite CuCrO2 Gas Sensors. ACS Appl Mater Interfaces. 2018;10(40):34727-34;PMID: 30207676. Available from: https: //doi.org/10.1021/acsami.8b10485.

31. Sianou AC. On the temperature dependence of the coefficient of thermal conductivity of polycrystalline $\mathrm{ZnCr} 2 \mathrm{O} 4$ and $\mathrm{MgCr} 2 \mathrm{O} 4$. Sci Ann Fac Phys Mathem, Univ Thessaloniki. 1978;18:165-80;.

32. Ono Y, Satoh K, Nozaki T, Kajitani T. Structural, Magnetic and Thermoelectric Properties of Delafossite-type Oxide, $\mathrm{CuCr} 1$ xMgxO2 ( $\leq \leq x \leq 0.05)$. Jpn J Appl Phys. 2007 Mar;46(3A):10715;Available from: https://doi.org/10.1143/JJAP.46.1071. 